\title{
Gas Vacuole Formation in Hormogonia of Nostoc muscorum
}

\author{
By R. E. ARMSTRONG, ${ }^{1}$ P. K. HAYES ${ }^{2}$ AND A. E. WALSBY ${ }^{2 *}$ \\ ${ }^{1}$ Marine Science Laboratories, Menai Bridge, Gwynedd LL59 5EH, Wales, U.K. \\ ${ }^{2}$ Department of Botany, University of Bristol, Woodland Road, Bristol BS8 1UG, U.K.
}

(Received 12 February 1982; revised 8 August 1982)

\begin{abstract}
Gas vacuole formation was induced in a strain of Nostoc muscorum when the culture medium was diluted with water. The induction also occurred when a single ingredient of the culture medium, $\mathrm{NaNO}_{3}$, was withdrawn. Replacing this ingredient with one of a number of salts $\left(\mathrm{NaCl}, \mathrm{KCl}, \mathrm{KNO}_{3}\right)$ in equiosmolar concentration prevented the induction, but replacing it with glucose or sucrose did not. Increased light intensity also induced gas vacuole formation. The combination of withdrawing $\mathrm{NaNO}_{3}$ and increasing light intensity gave a larger induction than the sum of each separately. Gas vacuoles disappeared about $3 \mathrm{~d}$ after formation. Their disappearance was accelerated by addition of chloramphenicol which led to collapse of the constitutive gas vesicles by rising cell turgor pressure. The induction of gas vesicles was accompanied by a number of other morphological changes representing the differentiation of hormogonia. Analysis of the cell protein extracts by polyacrylamide gel electrophoresis showed that de novo synthesis of the gas vesicle protein occurred during gas vacuole induction. A number of other proteins were also formed while others disappeared.
\end{abstract}

\section{INTRODUCTION}

The majority of planktonic cyanobacteria produce gas vacuoles constitutively but there are accounts of certain non-planktonic species which form these structures only under selected conditions. Canabaeus (1929) reported that in strains of both Tolypothrix rivularis and Calothrix epiphytica gas vacuole formation was restricted to the hormogonia, which differentiated at the tapering ends of trichomes; Singh \& Tiwari (1970) made similar observations with a related organism, described as Gloeotrichia ghosei. All three of these cyanobacteria would come under the genus Calothrix in the new classification of Rippka et al. (1979). Canabaeus (1929) also found that under certain conditions gas vacuoles were produced in trichomes of a cyanobacterium identified as Anabaena variabilis. She commented that the gas-vacuolate trichomes differed from the non-vacuolate ones in that they were narrower and lacked heterocysts. Trichomes differentiated in this way are now also regarded as hormogonia and Rippka et al. (1979) would place this organism in the genus Nostoc, distinguished from Anabaena by hormogonia production. Canabaeus (1929) reported that the differentiation of gas-vacuolate trichomes could be induced in this organism by culturing it in a medium containing a critical concentration of $\mathrm{NaCl}, 0 \cdot 8 \%(0 \cdot 14 \mathrm{M})$.

Waaland \& Branton (1969) reported that in Nostoc muscorum gas vacuole production was induced by diluting the culture medium with distilled water, and in subsequent studies, Waaland et al. (1971) demonstrated that gas vacuoles also formed when the culture was transferred to a higher incident light intensity. Other changes, including the loss of heterocysts and a diminution in cell size, accompany gas vacuole production in this strain (Rippka et al., 1979; Walsby, 1981) and again it is clear that these differentiated trichomes are hormogonia.

Abbreviations: GVP, gas vesicle protein; PST/T, pressure-sensitive turbidity/turbidity remaining after applying pressure. 
In this paper we describe an investigation into the changes in culture conditions which stimulate the production of gas-vacuolate hormogonia in $N$. muscorum. We have confined our attentions to the induction of gas vacuoles, which were measured specifically using the techniques described by Walsby (1973a) but we recognize that other differentiational changes also occurred. At the outset we tested the possibility that there might be only one factor which triggered gas vacuole production, increased light intensity; decreased self-shading might have explained the induction observed on subculturing or diluting a culture. However, we confirmed that changes in the culture medium and in light intensity would independently cause induction.

Gas vacuoles, visible under the light microscope, are made up of clusters of submicroscopic hollow cylinders called gas vesicles; these are made of a single species of protein. We have tested the possibility that the induction of gas vacuole formation is dependent on the induction of gas vesicle protein (GVP) synthesis, rather than on the assembly of previously synthesized GVP.

\section{METHODS}

Culture. Investigations were made initially with Nostoc muscorum strain 172 obtained from the Microgarden Culture Collection, Department of Botany, University of California, Berkeley, U.S.A., the strain used by Waaland \& Branton (1969). Subsequent investigations were made with axenic subcultures (PCC 6719) derived from this strain, obtained from the Pasteur Culture Collection (Institut Pasteur, 28 rue du Dr Roux, 75015 Paris, France).

Culture media. Two culture media were used, a modification of the medium described by Allen (1968), referred to below as medium A, and a modification of the medium described by Walsby \& Booker (1980), referred to as medium $\mathrm{B}$. These two media contained the following ingredients, concentrations in $\mathrm{mg} \mathrm{l}^{-1}$, medium $\mathrm{A}$ first, medium B next in parenthesis. $\mathrm{K}_{2} \mathrm{HPO}_{4} \cdot 3 \mathrm{H}_{2} \mathrm{O}, 40$ (39); $\mathrm{MgSO}_{4} .7 \mathrm{H}_{2} \mathrm{O}, 75(37 \cdot 5) ; \mathrm{CaCl}_{2} .2 \mathrm{H}_{2} \mathrm{O}, 36$ (9); citric acid, 6 (0); ferric ammonium citrate, $6(0)$; $\mathrm{Na}_{2}$ EDTA, 1 (6.3); $\mathrm{Na}_{2} \mathrm{CO}_{3}, 50$ (5); FeNaEDTA, 0 (1.3); $\mathrm{MnSO}_{4} .4 \mathrm{H}_{2} \mathrm{O}, 2.03(0.51) ; \mathrm{MoO}_{3}, 0.184(0.046) ; \mathrm{H}_{3} \mathrm{BO}_{3}, 2.85(0.71) ; \mathrm{ZnSO}_{4} .7 \mathrm{H}_{2} \mathrm{O}, 0.22(0.055) ; \mathrm{CuSO}_{4} .5 \mathrm{H}_{2} \mathrm{O}$, $0.079(0.019) ; \mathrm{Co}\left(\mathrm{NO}_{3}\right)_{2} .6 \mathrm{H}_{2} \mathrm{O}, 0.049(0.012)$.

Each of the media was prepared in two forms, with or without $\mathrm{NaNO}_{3}\left(1.5 \mathrm{gl}^{-1}\right)$, and then referred to as medium $\mathbf{A}+\mathbf{N}$ or $\mathbf{A}-\mathbf{N}(\mathbf{B}+\mathbf{N}$ or $\mathbf{B}-\mathbf{N})$, respectively.

Culture apparatus. Cultures were grown in Erlenmeyer flasks bubbled with air. For many experiments 1.81 cultures were grown in 2.51 capacity flasks under an incident intensity of 20 to $35 \mu \mathrm{E} \mathrm{m}^{-2} \mathrm{~s}^{-1}$ at room temperature or in an illuminated incubator at $18^{\circ} \mathrm{C}$. The mean light intensity in the culture decreased, to $5 \mu \mathrm{E} \mathrm{m}^{-2} \mathrm{~s}^{-1}$ or less, as the cyanobacteria grew. From these densely self-shaded cultures smaller replicate cultures were established after concentrating the cyanobacterium by settling and then centrifugation at $2900 \mathrm{~m} \mathrm{~s}^{-2}(296 \mathrm{~g})$ for $15 \mathrm{~min}$, and resuspending it in samples of fresh medium of equivalent total volume. The effects of different light intensities were investigated in the apparatus described by Walsby \& Booker (1980) with each small culture illuminated from below and supported by a neutral density filter. The mean light flux in each culture was determined from measurements of the light entering the culture from below $\left(E_{0}\right)$ and leaving above $\left(E_{\mathrm{D}}\right)$. The mean flux was calculated from the expression $E_{\mathrm{m}}=\left(E_{0}-E_{\mathrm{D}}\right) /\left(\ln E_{0}-\ln E_{\mathrm{D}}\right)$, given by Van Liere \& Walsby (1982). Measurements of light flux were made with a LiCor quantum sensor measuring in $\mu \mathrm{E} \mathrm{m}^{-2} \mathrm{~s}^{-1}$ between the wavelengths of 400 and $700 \mathrm{~nm}$.

Chemicals added to induce gas vacuole formation. The presence of $\mathrm{NaNO}_{3}\left(1.5 \mathrm{~g}^{-1}\right.$, equivalent to $\left.17.6 \mathrm{mM}\right)$, prevented gas vacuole induction when $N$. muscorum was transferred to fresh medium at low light intensity. To test whether other substances would prevent induction, they were added at concentrations giving a similar osmolarity, i.e. at $17.6 \mathrm{mM}$ for $\mathrm{NaCl}, \mathrm{KCl}$ and $\mathrm{KNO}_{3}$, and $35.2 \mathrm{mM}$ for the non-dissociating solutes sucrose, glucose and glycerol.

Measurement of relative gas-vacuolation and turgor pressure. An estimate of the relative gas vacuole content of $N$. muscorum cultures was obtained from the ratio PST/T. The PST is the pressure-sensitive turbidity of a sample, that part of the turbidity, generated by gas vacuoles, that disappears on the application of 13 bar pressure; $T$ is the turbidity, generated by other parts of the cell suspension, that remains after applying pressure. Turgor pressure of the $N$. muscorum cells was determined from the difference between the mean critical collapse pressures of the gas vesicles in (a) cells suspended in $0.5 \mathrm{M}$-sucrose and (b) cells suspended in culture medium (Walsby, 1971, 1980), using the pressure-nephelometer described by Walsby $(1973 a)$.

Electrophoretic separation of proteins. Filaments from cultures, before and after gas vacuole induction, were concentrated by filtration on to a $3 \mu \mathrm{m}$ pore size membrane filter and resuspended in water. Gas vesicles present were collapsed by pressurizing to 13 bar to prevent flotation and the filaments were concentrated by centrifugation at $20600 \mathrm{~m} \mathrm{~s}^{-2}(2100 \mathrm{~g})$ for $15 \mathrm{~min}$. The pellet was resuspended in $1 \mathrm{ml}$ water and $10 \mu \mathrm{l}$ phenylmethylsulphonyl fluoride. The cells were then ruptured by passage through a French press at $138 \mathrm{MPa}$. Immediately after rupture $200 \mu \mathrm{l}$ samples of the disrupted filaments were mixed with $200 \mu \mathrm{l}$ samples of a solvent mixture containing $5 \%(\mathrm{w} / \mathrm{v})$ 
SDS, 5 mM-EDTA, 2 mM-Tris, $10 \%$ (v/v) glycerol, $0.01 \%(w / v)$ bromophenol blue, and $0.01 \%(w / v)$ xylene cyanol FF (BDH). A standard suspension containing a concentration of $1 \mathrm{mg} \mathrm{m}^{-1}$ of gas vesicles isolated from Anabaena flos-aquae as described by Walsby \& Armstrong (1979), was prepared in the same way. The samples were boiled for $3 \mathrm{~min}$ and then applied to wells on a polyacrylamide slab gel in which the acrylamide concentration had been prepared in a stepped gradient from $20 \%(\mathrm{w} / \mathrm{v})$ at the bottom to $6 \%$ at the top, overlaid by a $5 \%$ acrylamide stacking gel; both gels contained $0.13 \%$ (w/v) SDS. The discontinuous buffer system of Laemmli (1970) was used. The trough buffer contained $50 \mathrm{~mm}$-Tris, $383 \mathrm{~mm}$-glycine and $0 \cdot 1 \%(\mathrm{w} / \mathrm{v}) \mathrm{SDS}$. The electrophoresis gel was run at a voltage which was increased by $10 \mathrm{~V}$ each hour from 30 to $60 \mathrm{~V}$ and then run for a further $16.5 \mathrm{~h}$. The gel was then stained for $60 \mathrm{~min}$ in Coomassie brilliant blue $[0.2 \%(\mathrm{w} / \mathrm{v})$ in $50 \%(\mathrm{v} / \mathrm{v})$ methanol and $7 \%(\mathrm{v} / \mathrm{v})$ acetic acid] and destained in $20 \%$ methanol and $7 \%$ acetic acid.

\section{RESULTS}

Gas vacuole production could be induced under a variety of conditions, as described below, but in preliminary experiments it was found that induction was poor in aged cultures or in subcultures set up from them. In subsequent experiments batch cultures less than 2 weeks old were used. In experiments in which the effect of changing the culture medium was investigated it was usually necessary to resuspend the $N$. muscorum in the new medium, as the removal of ingredients rather than their addition caused induction. Control treatments involved resuspending the $N$. muscorum filaments in fresh medium of the same composition as the original. If the filament concentration was thereby diluted, gas vacuole induction often occurred in the controls also, owing to the increased illumination resulting from decreased self-shading. This could be avoided by resuspending the filaments in medium of equal or less volume than the original culture, in both control and experimental treatments.

\section{Induction in distilled water}

Resuspension of filaments in the same volume of distilled water resulted in gas vacuole induction. Gas vacuole production reached a peak after $60 \mathrm{~h}$ and then declined (Fig. 1). The gas vacuoles that had formed then disappeared. Although this provided an effective method of inducing gas vacuole formation it was a drastic one, and a proportion of the filaments lysed. Subsequent experiments were carried out to determine whether it was necessary to omit all the mineral salts from the transfer medium or whether gas vacuoles could be induced by omitting particular salts.

\section{Induction by transfer to medium lacking $\mathrm{NaNO}_{3}$}

Abundant gas vacuoles were induced when $N$. muscorum was inoculated from a culture in $\mathrm{A}+$ $\mathrm{N}$ medium to $\mathrm{B}-\mathrm{N}$ medium. It was considered possible that the absence of $\mathrm{NaNO}_{3}$ in the latter caused the induction. In preliminary experiments it was found that addition of $\mathrm{NaNO}_{3}$ at a concentration of $1.5 \mathrm{~g} \mathrm{l}^{-1}$ to the B medium prevented the induction. Moreover, when $N$. muscorum was cultured in $\mathrm{B}+\mathrm{N}$ medium, transfer to $\mathrm{B}-\mathrm{N}$ medium gave induction whereas transfer to $\mathrm{B}+\mathrm{N}$ did not, unless there was a simultaneous increase in light intensity. As shown in Table 1, transfer to medium without $\mathrm{NaNO}_{3}$ and increased light intensity resulted in a level of induction which exceeded the sum of the inductions caused by each of these factors separately.

\section{Induction prevented by $\mathrm{NaCl}$ and other salts}

It was originally suspected that the combined nitrogen provided by $\mathrm{NaNO}_{3}$ rather than the salt concentration per se was the factor which suppressed induction in the above transfer, but this proved not to be the case. In a series of three experiments it was found, on each occasion, that no gas vacuole induction occurred when $N$. muscorum was transferred to the $\mathrm{A}-\mathrm{N}$ medium containing either $17.6 \mathrm{mM}-\mathrm{NaCl}$ or $17.6 \mathrm{~mm}-\mathrm{NaNO}_{3}$; in each case gas vacuole formation occurred in controls where neither of these salts were present. The results were substantially the same when the $N$. muscorum was transferred into the B medium, induction occurring in the absence of $\mathrm{NaCl}$ or $\mathrm{NaNO}_{3}$ but not in their presence. In one of these experiments it was found that $17.6 \mathrm{~mm}-\mathrm{KCl}$ or $\mathrm{KNO}_{3}$ in the transfer medium would also prevent gas vacuole induction. It therefore seemed that the effect of these salts was not mediated through any specific ion. In a 


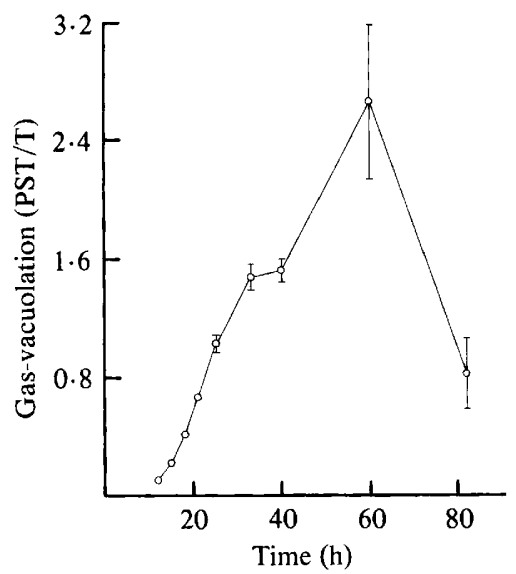

Fig. 1. Time course of gas vacuole formation by Nostoc muscorum following transfer from medium A + $\mathrm{N}$ to distilled water. The vertical bars represent $95 \%$ confidence limits.

Table 1. Induction of gas vacuoles on changing the culture medium and light intensity

$\begin{array}{cccc}\begin{array}{c}\text { Initial } \\ \text { medium }\end{array} & \begin{array}{c}\text { Final } \\ \text { medium }\end{array} & \begin{array}{c}\text { Light quantum } \\ \left(\mu \mathrm{E} \mathrm{m}^{-2} \mathrm{~s}^{-1}\right)\end{array} & \begin{array}{c}\text { Gas-vacuolation } \\ \text { at 48 h } \\ (\mathrm{PST} / \mathrm{T})\end{array} \\ \mathrm{B}+\mathrm{N} & \mathrm{B}+\mathrm{N} & 0 & 0.02 \\ \mathrm{~B}+\mathrm{N} & \mathrm{B}-\mathrm{N} & 0 & 1 \cdot 11 \\ \mathrm{~B}+\mathrm{N} & \mathrm{B}+\mathrm{N} & 64 & 0.63 \\ \mathrm{~B}+\mathrm{N} & \mathrm{B}-\mathrm{N} & 64 & 2.61\end{array}$

Table 2. Induction of gas vacuoles on transfer to culture media with different additional ingredients

$\begin{array}{cclccc}\begin{array}{c}\text { Initial } \\ \text { medium }\end{array} & \begin{array}{c}\text { Final } \\ \text { medium }\end{array} & \begin{array}{c}\text { Additional } \\ \text { ingredient }\end{array} & \text { At } 24 \mathrm{~h} & \text { At } 48 \mathrm{~h} & \text { At } 72 \mathrm{~h} \\ \mathrm{~A}+\mathrm{N} & \mathrm{B}-\mathrm{N} & - & 0.42 & 0.66 & 0.67 \\ \mathrm{~A}+\mathrm{N} & \mathrm{B}+\mathrm{N} & \left(\mathrm{NaNO}_{3}\right) & 0.07 & 0.07 & 0.06 \\ \mathrm{~A}+\mathrm{N} & \mathrm{B}-\mathrm{N} & \mathrm{NaCl} & 0.08 & 0.11 & 0.09 \\ \mathrm{~A}+\mathrm{N} & \mathrm{B}-\mathrm{N} & \mathrm{KCl} & 0.06 & 0.07 & 0.05 \\ \mathrm{~A}+\mathrm{N} & \mathrm{B}-\mathrm{N} & \text { Sucrose } & 0.24 & 0.33 & 0.28 \\ \mathrm{~A}+\mathrm{N} & \mathrm{B}-\mathrm{N} & \text { Glucose } & 0.32 & 0.44 & 0.45 \\ \mathrm{~A}+\mathrm{N} & \mathrm{B}-\mathrm{N} & \text { Glycerol } & 0.23 & 0.27 & 0.23\end{array}$

further experiment the effects of these ionic and other non-ionic solutes, added to the transfer medium at equal osmolarity, was investigated (see Table 2). In general it was found that induction occurred in the presence of the non-ionic solutes, but not in the presence of ionic ones. In further experiments we found that none of the substances added inhibited the growth of the cyanobacterium at the concentrations used. Their effect in preventing gas vacuole induction therefore appears to be specific.

\section{Sequential induction by changes of medium}

Nostoc muscorum did not form gas vacuoles in the $\mathrm{B}+\mathrm{N}$ medium under low light intensity but it did form them for a time after transfer to the $\mathrm{B}-\mathrm{N}$ medium, and the filaments became buoyant. After $3 \mathrm{~d}$ the filaments started to lose their gas vacuoles and sank. The alga could grow without gas vacuoles in the medium which caused it to produce them. However, it was possible to induce further production of gas vesicles by transferring the filaments from the $\mathrm{B}-\mathrm{N}$ medium to distilled water. 


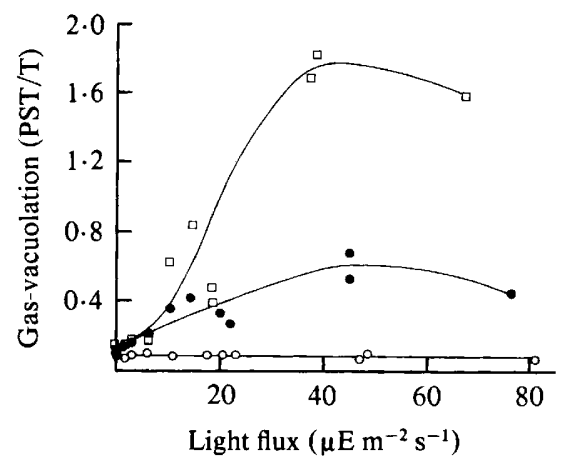

Fig. 2

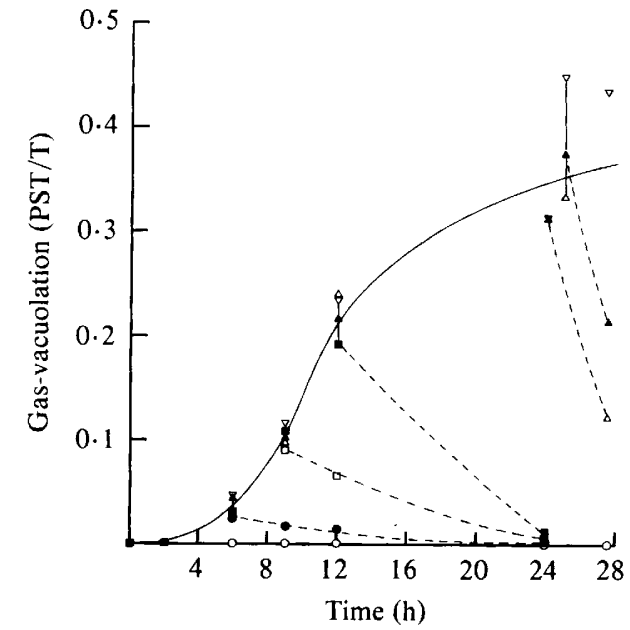

Fig. 3

Fig. 2. Relative gas vacuole formation by Nostoc muscorum after transfer to different light intensities, $\mathrm{O}, 0 \mathrm{~h} ; \mathrm{O}, 24 \mathrm{~h} ; \square, 48 \mathrm{~h}$ after transfer.

Fig. 3. Relative gas vacuole formation by Nostoc muscorum after transfer from medium $\mathbf{B}+\mathbf{N}$ to $\mathbf{B}-$ $\mathrm{N}$ and to an increased light intensity, a quantum flux of $70 \mu \mathrm{E} \mathrm{m}^{-2} \mathrm{~s}^{-1}$ (solid line). Gas vacuole disappearance occurred after addition of chloramphenicol at times indicated by change to broken lines.

\section{Effect of light intensity}

Waaland et al. (1971) reported that gas vacuole formation was induced when the light intensity incident on the culture was increased from 300 to $450 \mathrm{ft}$-candle (i.e. 3.2 to $4.8 \mathrm{klx}$, probably equivalent to 53 to $79 \mu \mathrm{E} \mathrm{m}^{-2} \mathrm{~s}^{-1}$ under the white fluorescent lamps they used; see Table of Van Liere \& Walsby, 1982) but they did not carry out quantitative investigations. We therefore looked at the effect of a shift up to a range of light intensities on gas vacuole formation and estimated the relative change in gas-vacuolation from the change in pressure-sensitive turbidity. There was very little gas vacuole formation when the cyanobacterium was transferred to a radiant flux of less than $7 \mu \mathrm{E} \mathrm{m}^{-2} \mathrm{~s}^{-1}$ but significant formation occurred at higher light fluxes (Fig. 2). The largest increases were found after transfer to $35 \mu \mathrm{E} \mathrm{m}^{-2} \mathrm{~s}^{-1}$ and above.

\section{Inhibition of gas vacuole formation by chloramphenicol}

Gas vacuole formation is dependent on the synthesis of the gas vesicle protein and, as shown by Konopka et al. (1975) in the heterotrophic bacterium Microcyclus aquaticus, the process is inhibited by chloramphenicol. We investigated the effect of this protein-synthesis inhibitor on gas vacuole formation by $N$. muscorum, following induction by transfer from $\mathrm{B}+\mathrm{N}$ to $\mathrm{B}-\mathrm{N}$ medium and simultaneous increase in light intensity to $70 \mu \mathrm{E} \mathrm{m}^{-2} \mathrm{~s}^{-1}$. Gas vacuole production increased steadily for $27 \mathrm{~h}$ and more when no chloramphenicol was added, but when the inhibitor was added to cultures at different times after induction, production abruptly ceased and the gas vacuoles which had formed then disappeared (Fig. 3).

\section{Chloramphenicol stimulates rise in cell turgor pressure}

In a related cyanobacterium, Anabaena flos-aquae, rise in cell turgor pressure stimulated by transfer to high light intensity (Walsby, 1971) in the presence of carbon dioxide and potassium salts can cause collapse of a proportion of the gas vesicles within a cell (Dinsdale \& Walsby, 1972; Allison \& Walsby, 1981). We investigated the cell turgor pressure and range of critical collapse pressure of gas vesicles in $N$. muscorum to see if their disappearance in the presence of chloramphenicol was caused by turgor pressure rise.

From the collapse/pressure curves (Fig. 4) it is seen that the gas vesicles of $N$. muscorum had a mean critical pressure of $5.3 \mathrm{bar}$, before the chloramphenicol was added, and the cells had a 


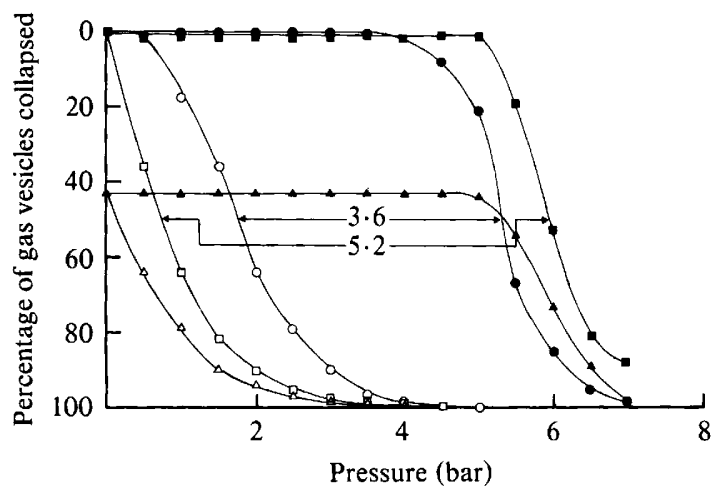

Fig. 4. Collapse of gas vacuoles with pressure in Nostoc muscorum. Open symbols, filaments suspended in culture medium; solid symbols, filaments suspended in $0.5 \mathrm{M}$-sucrose. $(a) \mathrm{O}, \mathrm{O}$, In cells $25 \mathrm{~h}$ after gas vacuole induction; (b) $\square, \square, 27.5 \mathrm{~h}$ after gas vacuole induction, the last $2.5 \mathrm{~h}$ in the presence of chloramphenicol; (c) $\triangle, \Delta$, the same data as in $(b)$, plotted at 0.57 of the value in $(b)$ (this is the proportion of gas vesicles which survive the turgor pressure rise).

turgor pressure of 3.6 bar. In the turgid cells (suspended in culture medium without sucrose) the weakest gas vesicles required an applied pressure of 0.5 bar to collapse them. After transfer to chloramphenicol for $1 \mathrm{~h}$ it was found that the turgor pressure had risen to $4.5 \mathrm{bar}$ and after $2.5 \mathrm{~h}$ it had risen to 5.2 bar, i.e. 1.6 bar above its original value. This is well above the pressure required to collapse the weakest gas vesicles originally present in the turgid cells; in fact the original collapse/pressure curve shows that $42 \%$ of the gas vesicles collapsed under a pressure increase of 1.6 bar. The ratio of PST/T, which indicates the relative state of cell gas-vacuolation, dropped from 3.74 to 2.13 in the $2.5 \mathrm{~h}$ after adding chloramphenicol (Fig. 3), a change of $43 \%$, in close agreement with the change predicted from the observed turgor pressure rise. It is concluded, therefore, that the loss of gas vesicles which followed addition of chloramphenicol was caused by collapse under rising turgor pressure.

Further evidence that gas vesicle collapse occurred is given by the change in collapse/pressure curves (Fig. 4) with cells suspended in hypertonic sucrose. (These curves give the true critical pressure distribution of the gas vesicles.) It is seen that the gas vesicles which survived the turgor pressure rise have a critical pressure distribution which corresponds with those of the strongest vesicles originally present. The comparison is more easily made with the derivative curve plotted from $43 \%$ collapse, the percentage already lost by turgor pressure rise.

\section{Changes in buoyancy}

In many of the experiments described above a proportion, often the majority, of the filaments present in a culture became buoyant and floated when gas vacuoles were formed. The buoyancy was lost when such cultures were exposed to a pressure of 13 bar, causing gas vacuole collapse. Buoyancy was also lost when the gas vacuoles disappeared naturally from the filaments, usually within 3 or $4 \mathrm{~d}$ of induction.

\section{Induction of the gas vesicle protein}

The formation of gas vacuoles in Nostoc muscorum depends on the synthesis of gas vesicle protein (GVP) and the assembly of this protein into gas vesicles. The inhibition of gas vacuole induction by chloramphenicol suggested that the synthesis of GVP occurs during induction. We analysed the cell proteins by SDS-PAGE to see if the synthesis of GVP could be detected during induction. There was a prominent Coomassie-blue staining band that ran with nearly the same mobility as Anabaena flos-aquae GVP, which was present in the protein extract of Nostoc muscorum after but not before gas vacuole induction (Fig. 5). The mobility of this band indicates a molecular weight in the region of 20000 , the revised figure for GVP (J. E. Walker \& A. E. Walsby, unpublished). The relative staining intensity suggests that GVP is about the fifteenth most abundant protein present. 


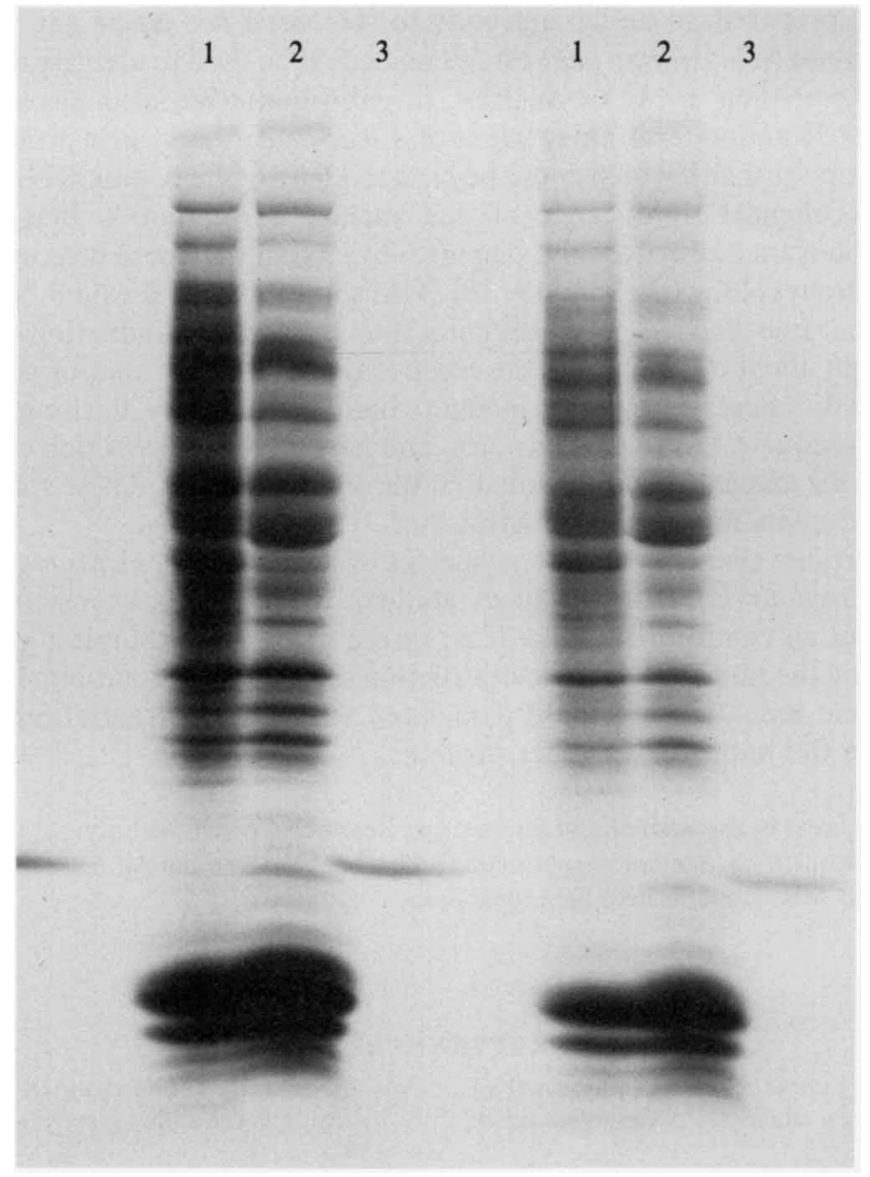

Fig. 5. Separation of proteins by SDS-PAGE. Tracks: 1, Nostoc muscorum extract before induction of gas-vacuolate hormogonia; $2, N$. muscorum extract after induction; 3 , isolated gas vesicles from Anabaena flos-aquae. $30 \mu \mathrm{l}$ samples were loaded in the left-hand set of wells, $20 \mu \mathrm{l}$ samples were loaded in the right-hand set.

The presence of the GVP band after induction is the most obvious change in the pattern of proteins because the band occurs in a region on the gel, behind the intensely staining phycobiliproteins, where there are no other abundant proteins. However, examination of the banding pattern reveals that there are at least a dozen other proteins which show marked changes in abundance; about half of them appear or increase after hormogonia induction while the others disappear or decrease. The identity of none of these other bands is known at present. Some of these proteins may be involved in some way in the morphological changes which occur during the differentiation of hormogonia (see Fig. 51 of Rippka et al., 1979).

\section{DISCUSSION}

Nostoc muscorum is evidently unable to maintain gas vacuoles in its cells indefinitely. The structures are produced in response to a change in conditions and are then subsequently lost. It appears to be the change rather than the new conditions per se which results in gas vacuole induction.

When hormogonia are differentiated in Nostoc muscorum, numerous changes must occur at the subcellular level. The formation of gas vacuoles may be the change which is easiest to study since the gas vesicle protein can now be identified by electrophoresis and is produced in such large quantities that it must require the transcription of large quantities of, or relatively stable, 
mRNA. We have prepared an active antibody to Anabaena flos-aquae gas vesicles which is highly cross reactive to $N$. muscorum gas vesicles and could be used to identify the GVP-mRNA complex (R. E. Armstrong \& A. E. Walsby, unpublished). We also have the amino acid sequence of the first 58 amino-terminal residues of $A$. flos-aquae gas vesicle protein (J. E. Walker \& A. E. Walsby, unpublished), which could be used to identify the coding RNA base sequence.

The probable ecological significance of gas vacuole formation is that it provides the hormogonia with buoyancy and aids their dispersal by enabling them to float away from the site occupied by the parent colony (Walsby, 1973b). This sort of dispersal would become possible if the original site became flooded, and this puts into context the induction of gas-vacuolate hormogonia brought about by changes in the composition of the surrounding solution. Flooding might also indirectly cause changes in incident light intensity by flushing away overlying sediments. The subsequent loss of gas vacuoles, and hence buoyancy, which occurs after a few days would permit the dispersed hormogonia to settle on to a new site. These speculations should be tested by experiments in the natural habitat of Nostoc muscorum.

In various planktonic cyanobacteria (e.g. species of Anabaena, Aphanizomenon, Gloeotrichia, Microcystis and Oscillatoria) that we have studied in culture gas vesicles are produced constitutively under all conditions and, at least in the first three examples, gas-vacuolation is regulated by varying the rate of gas vesicle destruction rather than formation. The only clear-cut cases of gas vacuole induction are those associated with the differentiation of hormogonia, which also involve the induction of other proteins.

This work was supported by the Science and Engineering Research Council with a grant to A. E. Walsby and studentship to R. E. Armstrong. We are very grateful to Drs J. E. Walker and M. Tanner for their advice on electrophoresis, and to Miss Annette Bees for preparation of cultures.

\section{REFERENCES}

ALLEN, M. M. (1968). Simple conditions for growth of unicellular blue-green algae on plates. Journal of Phycology 4, 1-4.

Allison, E. M. \& WalsBy, A. E. (1981) The role of potassium in the control of turgor pressure in a gas vacuolate blue-green alga. Journal of Experimental Botany 32, 241-249.

Canabaeus, L. (1929). Über die Heterocysten und Gasvakuolen der Blaualgen und ihre Beziehung zueinander. Pflanzenforschung 13, 1-48.

Dinsdale, M. T. \& Walsby, A. E. (1972). The interrelations of cell turgor pressure, gas vacuolation and buoyancy in a blue-green alga. Journal of Experimental Botany 75, 561-570.

Konopka, A. E., Staley, J. T. \& Lara, J. C. (1975). Gas vesicle assembly in Microcyclus aquaticus. Journal of Bacteriology 122, 1301-1309.

LAEMMLI, U.K. (1970). Cleavage of structural proteins during the assembly of the head of bacteriophage T4. Nature, London 227, 680-685.

Rippka, R., Deruelles, J., Waterbury, J. B., Herdman, M. \& Stanier, R. Y. (1979). Generic assignments, strain histories and properties of pure cultures of cyanobacteria. Journal of General Microbiology 111, 1-61.

Singh, R. N. \& Tiwari, D. N. (1970). Frequent heterocyst germination in the blue-green alga Gloeotrichia ghosei Singh. Journal of Phycology 6, 172-176.

VAN LIERE, E. \& WALSBY, A. E. (1982). Interactions of cyanobacteria with light. In The Biology of Cyanobacteria, pp. 9-45. Edited by N. G. Carr \& B. A. Whitton. Oxford: Blackwell Scientific Publications.
WAALAND, J. R. \& Branton, D. (1969). Gas vacuole development in a blue-green alga. Science 163, 13391341.

WaAland, J. R., WaAland, S. D. \& Branton, D. (1971). Gas vacuoles. Light shielding in blue-green algae. Journal of Cell Biology 48, 212-215.

WALSBY, A. E. (1971). The pressure relationships of gas vacuoles. Proceedings of the Royal Society of London B178, 301-326.

WALSBY, A. E. (1973a). A portable apparatus for measuring relative gas vacuolation, the strength of gas vacuoles, and turgor pressure in planktonic bluegreen algae and bacteria. Limnology and Oceanography 18, 653-658.

WALSBY, A. E. (1973b). Gas vacuoles. In The Biology of Blue-Green Algae, pp. 340-352. Edited by N. G. Carr \& B. A. Whitton. Oxford: Blackwell Scientific Publications.

WALSBY, A. E. (1980). The water relations of gasvacuolate prokaryotes. Proceedings of the Royal Society of London B208, 73-102.

WALSBY, A. E. (1981). Cyanobacteria: planktonic gasvacuolate forms. In The Prokaryotes, pp. 224-235. Edited by M. Starr, H. Stolp, H. Truper, A. Balows \& H. G. Schlegel. Berlin: Springer-Verlag.

WalsBY, A. E. \& ARMSTRONG, R. E. (1979). Average thickness of the gas vesicle wall in Anabaena flosaquae. Journal of Molecular Biology 129, 279-285.

WalsbY, A. E. \& Booker, M. J. (1980). Changes in buoyancy of a planktonic blue-green alga in response to light intensity. British Phycological Journal 15, 311-319. 